\title{
Finite element analysis for die casting parameters in high-pressure die casting process
}

\author{
Xin-yu Qin, *Yong Su, Jian Chen, Lan-jun Liu \\ School of Materials Science and Engineering, Hefei University of Technology, Hefei 230009, China
}

\begin{abstract}
The gating system and the overflow system were designed according to the casting structure during high pressure die casting (HPDC) process. The simulation was carried out by ProCAST software to visualize the injection chamber pre-crystallization and the flow of molten metal. The main work is to research four die casting process parameters, i.e. injection temperature, low-pressure velocity, high- and low-pressure velocity's switching position, and high-pressure velocity. Experimental results show that the higher injection temperature and lowpressure velocity can mitigate the pre-crystallization of the injection chamber. However, when the low-pressure velocity exceeds $0.2 \mathrm{~m} \cdot \mathrm{s}^{-1}$, the air entrapment in the chamber occurs. Besides, when the high-pressure velocity is greater than $2.5 \mathrm{~m} \cdot \mathrm{s}^{-1}$, the overflow channel at the final filling position is covered by the liquid metal too early. Finally, the injection temperature of $650{ }^{\circ} \mathrm{C}$, the low-pressure velocity of $0.2 \mathrm{~m} \cdot \mathrm{s}^{-1}$, the high- and low-pressure velocity's switching position of $320 \mathrm{~mm}$ and the high-pressure velocity of $2 \mathrm{~m} \cdot \mathrm{s}^{-1}$ are obtained as the optimal parameters by the software simulation, which has been verified by actual production.
\end{abstract}

Key words: aluminum alloy; die casting process; simulation optimization

CLC numbers: TG146.21 Document code: A

Article ID: 1672-6421/2019 04-272-05

\begin{abstract}
$\mathrm{A}$ luminum alloy die casting technology is a forming method that fills the cavity with liquid metal at a high velocity and solidifies under a high pressure. Current research on die casting mainly focuses on interfacial heat transfer, injection velocity, die casting temperature and so on. Paliani ${ }^{[1]}$ established an inverse model through experiments, and obtained that the heat transfer coefficient between liquid metal and injection chamber was about $1.2 \mathrm{~kW} \cdot \mathrm{m}^{-2} \cdot \mathrm{K}^{-1}$. El-Mahallawy ${ }^{[2]}$ pointed out that the density of the casting decreases with the increase of gate velocity. Pitsaris ${ }^{[3]}$ pointed out that the die casting temperature had the greatest influence on the mechanical properties of the die castings. With increasing the die casting temperature, the precrystallization content of the chamber decreased, and the mechanical properties of the castings were improved. Syrcros ${ }^{[4]}$ considered that injection velocity, casting temperature, filling time and pressure are the main factors affecting the quality of die castings.
\end{abstract}

With the development of computer technology, to

\section{*Yong Su}

Male, Ph.D., Professor. Research interest: digital precision forming technology.

E-mail: suyong1963@126.com

Received: 2019-01-28; Accepted: 2019-03-28 visualize high pressure die casting (HPDC) is more and more convenient. In this work, ProCAST finite element analysis software was used to visualize the diecasting process parameters in the HPDC process. The purpose is to reveal the rules of die casting for shell parts by studying the die casting process of a single representative shell part.

\section{Design for pouring system}

The shell die casting (hereinafter referred to as the casting) is studied in this work. The material of the casting is ADC12 aluminium alloy. The shape of the casting is shown in Fig. 1(a). The average wall thickness of the casting was calculated to be $5.31 \mathrm{~mm}$ with the maximum of $23.77 \mathrm{~mm}$ by using the rolling ball method of UG software. The volume of the castings was calculated by UG software to be $586,796.9086 \mathrm{~mm}^{3}$, and the mass of the castings was about $2.744 \mathrm{~kg}$. The wall thickness distribution of the casting is shown in Fig. 1(b), it can be found that the wall on the left side of the casting is thicker. Considering the wider channel can lead to the lower resistance to the flow of liquid metal ${ }^{[5]}$, the inner gate position is set at the place of the thicker wall, circled by the yellow outline.

In addition, the inner gate was designed with edge- 


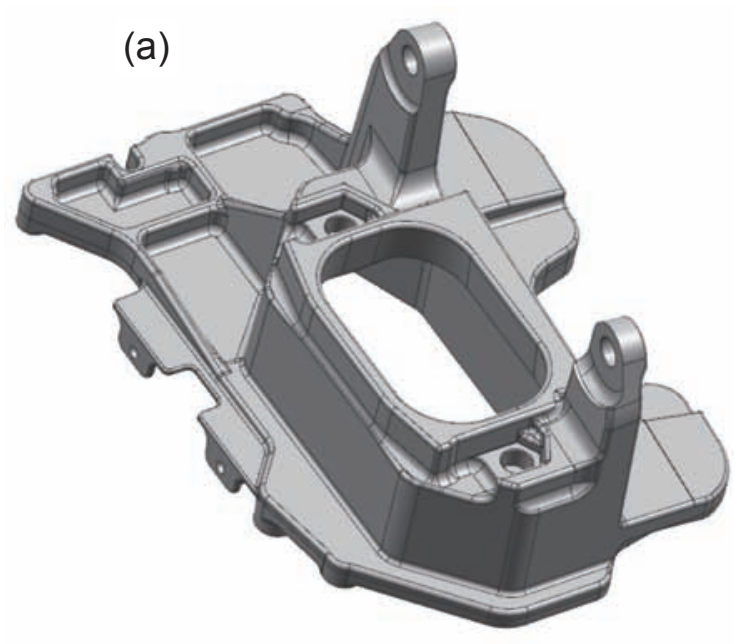

(b)

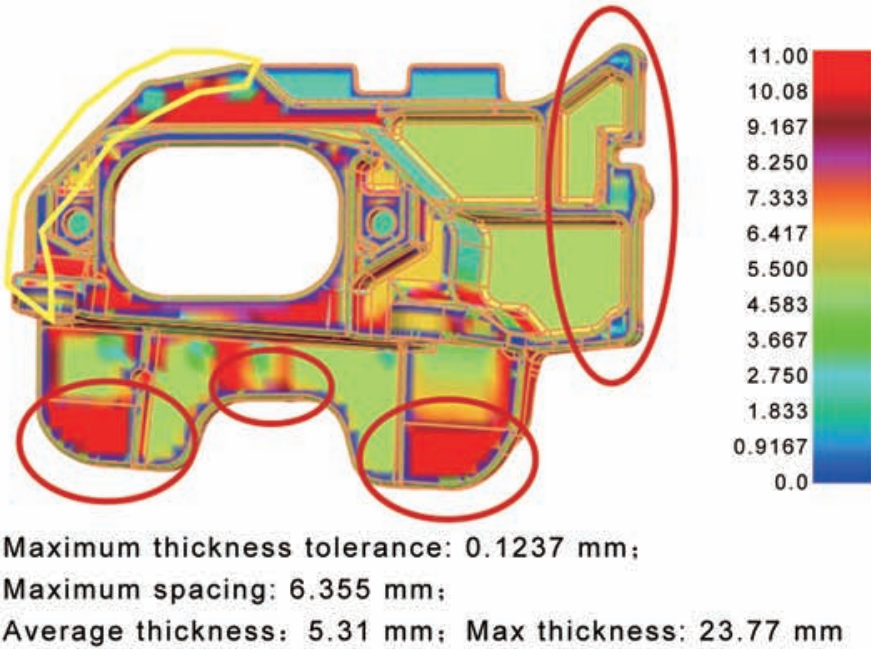

Fig. 1: (a) Three-dimensional casting model; (b) Wall thickness distribution of casting

lapping ${ }^{[6]}$. The cross-sectional area of the gate could be calculated by Eq. (1).

$$
A_{\mathrm{g}}=V / v t
$$

where, $A_{\mathrm{g}}$ is the cross-sectional area of the inner gate $\left(\mathrm{mm}^{2}\right) ; V$ is the sum of the volume of die casting and overflow groove, which is $650,000 \mathrm{~mm}^{3} ; v$ is the filling velocity of the molten metal at the gate, which is $25,000 \mathrm{~mm} \cdot \mathrm{s}^{-1} ; t$ is the filling time which is $0.06 \mathrm{~s}^{[6-9]}$. The calculated area of the inner gate is $\sim 430 \mathrm{~mm}^{2}$. the calculated cross-sectional area of the runner is $1,290 \mathrm{~mm}^{2}$, and the ratio of it to cross-sectional area of the gate is $1: 3^{[6-9]}$. A branch was drawn on the right side of the runner to collect the cold metal liquid and to improve the quality of the casting. The casting method was selected as horizontal cold chamber die casting, and a suitable injection chamber was required when designing the sprue. The selected injection chamber is $75 \mathrm{~mm}$ in diameter and $500 \mathrm{~mm}$ in length. The sprue width is $1 / 3$ the radius of the injection chamber, and the radius is the same as that of the injection chamber ${ }^{[7]}$. The locations circled by the red lines in Fig. 1(b) are the thicker edge and the last filling position, and some overflow slots were added for these locations ${ }^{[6]}$. To increase the connection effect of the four walls of the casting, an overflow tank was added at the top to enhance gas circulation ${ }^{[7-9]}$. Based on the above analysis, the gating system and the overflow system were designed and is shown in Fig. 2.

\section{Simulation and parameter optimization}

ProCAST software was used to visualize the die casting process and optimize the parameters of die casting, such as temperature, low-pressure velocity, high- and low-pressure velocity's switching position, and high-pressure velocity ${ }^{[7]}$. The heat transfer coefficient of the chamber is selected from Paliani's research result of $1,200 \mathrm{~kW} \cdot \mathrm{m}^{-2} \cdot \mathrm{K}^{-1}$ and that of the mold is chosen to be $4,000 \mathrm{~kW} \cdot \mathrm{m}^{-2} \cdot \mathrm{K}^{-1}$ according to the actual mold opening time ${ }^{[1]}$. To make the simulated state closer to that of the production state, a punch is used to push the molten metal into the injection chamber. According to the above description, the obtained simulated geometry mesh is shown in Fig. 3.

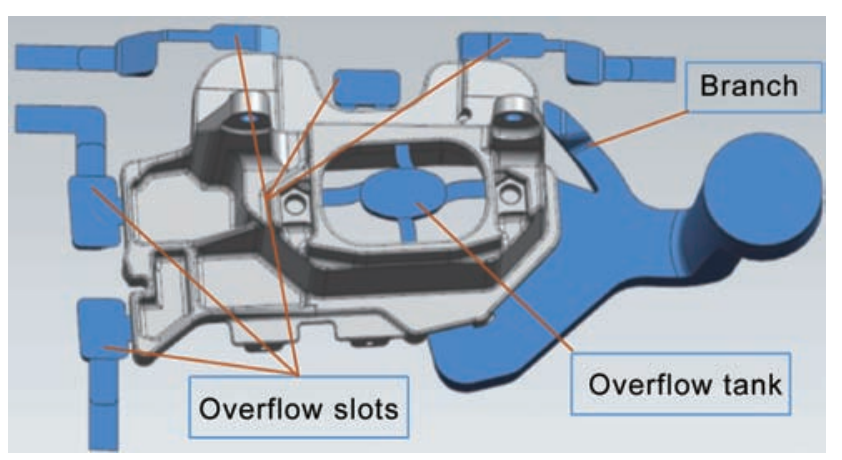

Fig. 2: Schematic diagram of pouring scheme

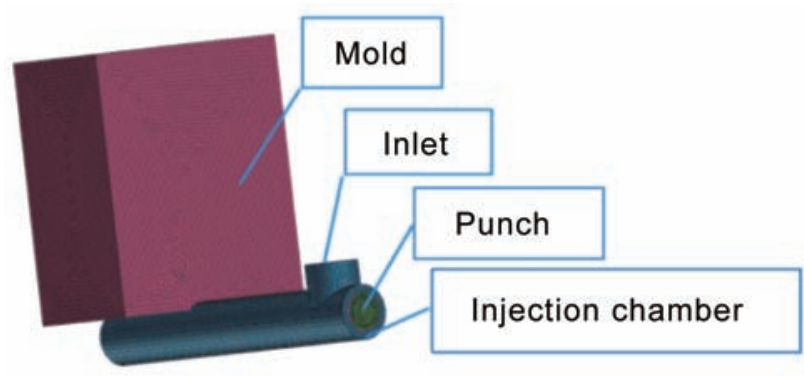

Fig. 3: Schematic diagram of geometric model

\subsection{Low-pressure velocity and injection temperature}

In the process of die casting, the velocity of the liquid metal driven by the punch into the chamber is called low-pressure velocity. It is beneficial to the discharge of the injection chamber gas and minimize the injection chamber precrystallization ${ }^{[8]}$. Generally, the low-pressure velocity does not exceed $0.3 \mathrm{~m} \cdot \mathrm{s}^{-1}$. The velocities and temperatures in this work are shown in Table 1. 
Since these three temperatures of the aluminium alloy in Table 1 are above the liquidus, it is not necessary to study the flow state of the liquid metal at different temperatures and at the same velocity ${ }^{[8]}$. The velocity test was carried out at a die casting temperature of $640{ }^{\circ} \mathrm{C}$, and the low-pressure velocity was started after the punch closed the pouring hole. The simulation results for the HPDC process with the three lowpressure velocities are shown in Fig. 4.

In Fig. 4 (a), it can be seen that although the filling rate is stable at $0.1 \mathrm{~m} \cdot \mathrm{s}^{-1}$, the pre-crystallization occurs in the chamber, which is detrimental to the quality of the casting.

Table 1: Velocity and temperature in this work

\begin{tabular}{cccc|}
\hline Parameters & A & B & C \\
\hline Low-pressure velocity $\left(\mathrm{m} \cdot \mathrm{s}^{-1}\right)$ & 0.1 & 0.2 & 0.3 \\
Injection temperature $\left({ }^{\circ} \mathrm{C}\right)$ & 640 & 650 & 660 \\
\hline
\end{tabular}

At the velocity of $0.2 \mathrm{~m} \cdot \mathrm{s}^{-1}$ in Fig. 4(b), it is easy to observe that the pre-crystallization occurs at the end of the injection chamber and at the punch position. In the punch position, the molten metal is at the peak, which can avoid residual gas in the injection chamber. Figure 4(c) shows that a serious air entrapment presents near the punch. In summary, the lowpressure velocity is preferably selected to be $0.2 \mathrm{~m} \cdot \mathrm{s}^{-1}$.

The HPDC process with the three different injection temperatures $\left(640,650\right.$ and $\left.660{ }^{\circ} \mathrm{C}\right)$ were simulated, and the results are shown in Fig. 5, revealing that the pre-crystallization area at the end of the chamber decreases with increasing the die casting temperature. A large amount of pre-crystallization occurs at $640{ }^{\circ} \mathrm{C}$, but there is not an obvious difference in the amount of pre-crystallization between the HPDC processes with $650^{\circ} \mathrm{C}$ and $660{ }^{\circ} \mathrm{C}$. In order to prevent the coarse grains of molten metal due to the high injection temperature, the lower one of $650{ }^{\circ} \mathrm{C}$ is chosen as the different injection temperatures.
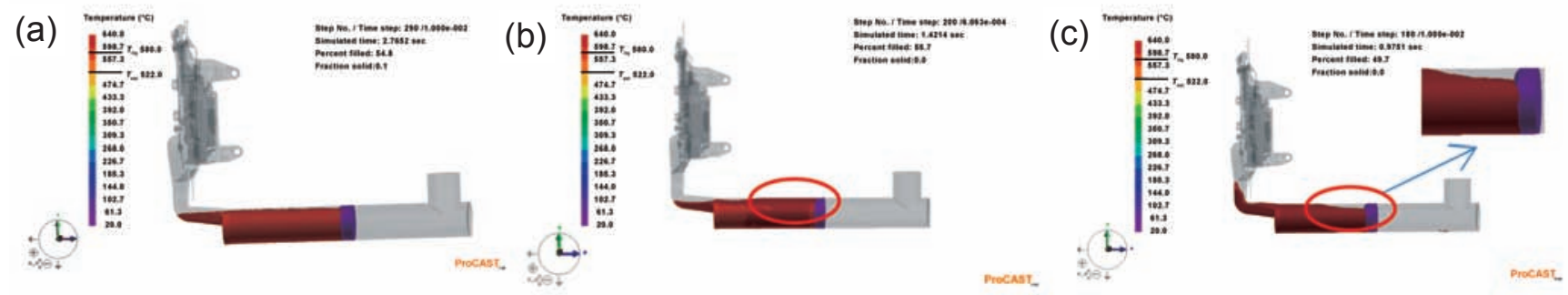

Fig. 4: Filling diagram for different low-pressure velocities:

(a) $0.1 \mathrm{~m} \cdot \mathrm{s}^{-1}$

(b) $0.2 \mathrm{~m} \cdot \mathrm{s}^{-1}$, (c) $0.3 \mathrm{~m} \cdot \mathrm{s}^{-1}$

(a)

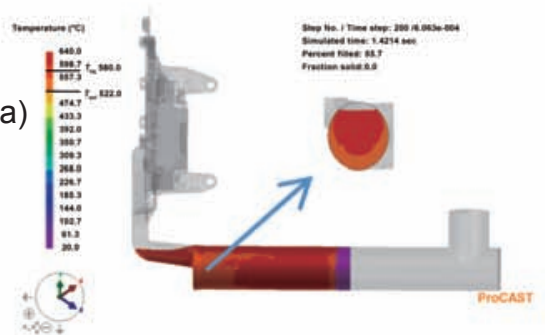

(b)

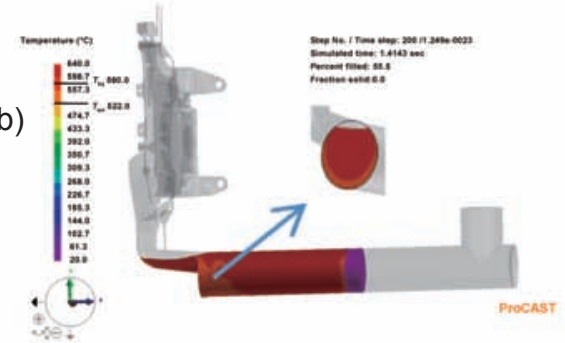

(c)

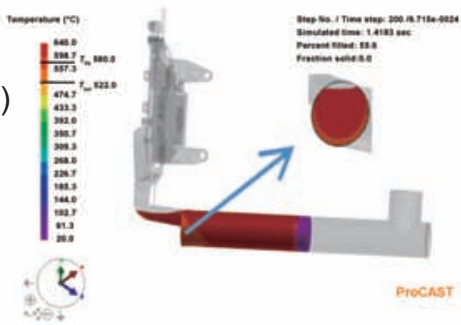

Fig. 5: Pre-crystallization diagram of different injection temperatures: (a) $640^{\circ} \mathrm{C}$, (b) $650^{\circ} \mathrm{C}$, (c) $660^{\circ} \mathrm{C}$

\subsection{Switching position of low- and high- pressure velocity}

In order to obtain a better switching position between the lowand high-pressure velocity, three gradient experiments were set up during the period of chamber filling and inner gate filling. The experimental parameters are: the injection temperature of $650{ }^{\circ} \mathrm{C}$, the low-pressure velocity of $0.2 \mathrm{~m} \cdot \mathrm{s}^{-1}$, and the punch switching positions of 300,320 and $340 \mathrm{~mm}$. The experimental results are shown in Fig. 6.

At the same filling percentage $(61.3 \%)$, it can be seen in Fig. 6 that the air entrapment occurred in the injection chamber with punch switching positions of 300 and $340 \mathrm{~mm}$ (Fig. 6 a and c), and no air entrapment occurred in the injection chamber with the punch switching position of $320 \mathrm{~mm}$ (Fig. 6b). This phenomenon is related to the movement of the molten metal in the runner. When the liquid metal enters the runner, the surface of the liquid fluctuates due to its steering. But when the high velocity is switched at the $320 \mathrm{~mm}$ position, the liquid metal is effectively filled with the position where it is about to generate air entrapment.

\subsection{High-pressure velocity}

At the end of the low-pressure velocity, the punch moves faster, and the velocity of the punch is the high-pressure velocity, which can be calculated by Eq. (2).

$$
A_{1} v_{1}=A_{\mathrm{g}} v
$$


where, $v_{1}$ is the injection velocity $\left(\mathrm{m} \cdot \mathrm{s}^{-1}\right) ; v$ is the filling velocity $\left(\mathrm{m} \cdot \mathrm{s}^{-1}\right) ; A_{1}$ is the cross-sectional area $\left(\mathrm{mm}^{2}\right)$ of the injection punch (approximate chamber); $A_{\mathrm{g}}$ is the crosssectional area $\left(\mathrm{mm}^{2}\right)$ of the inner gate. The value of $A_{1}$ can be calculated from the diameter of the injection chamber, and the values of $A_{\mathrm{g}}\left(\sim 430 \mathrm{~mm}^{2}\right)$ and $v\left(25,000 \mathrm{~mm} \cdot \mathrm{s}^{-1}\right)$ are described in the Section 1. The value of $A_{1}$ is $\sim 4,416 \mathrm{~mm}^{2}$, and the value of $v_{1}$ is $\sim 2,434 \mathrm{~mm} \cdot \mathrm{s}^{-1}$. To verify the reliability of the calculated high-pressure velocity, three sets of parameters, 2 , 2.5 and $3 \mathrm{~m} \cdot \mathrm{s}^{-1}$, are set to simulate the HPDC process with the different high-pressure velocities. The filling situation was observed when the filling ratios of the cavity were $70 \%, 80 \%$ and $90 \%$.The experimental results are shown in Fig. 7.

According to Fig. 7, it is clear that the overflow channel at the last filling position is covered by the liquid metal too early at the velocity of 2.5 and $3 \mathrm{~m} \cdot \mathrm{s}^{-1}$, which could affect the exhaust effect. The greater the filling velocity, the more the liquid metal splashes, and the more obvious the blockage of the overflow channel. It can be concluded that the velocity of $2 \mathrm{~m} \cdot \mathrm{s}^{-1}$ is the most suitable one among the above three parameters.
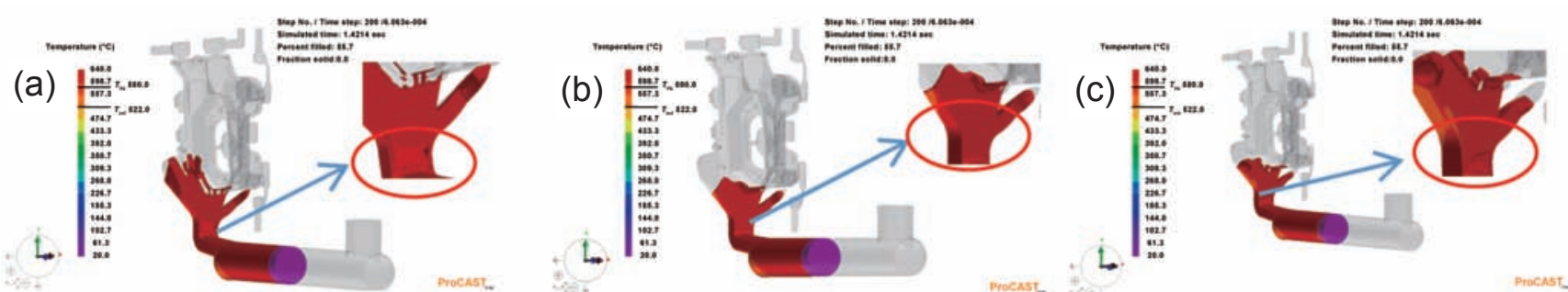

Fig. 7: Filling diagram of different switching positions: (a) $300 \mathrm{~mm}$, (b) $320 \mathrm{~mm}$, (c) $340 \mathrm{~mm}$

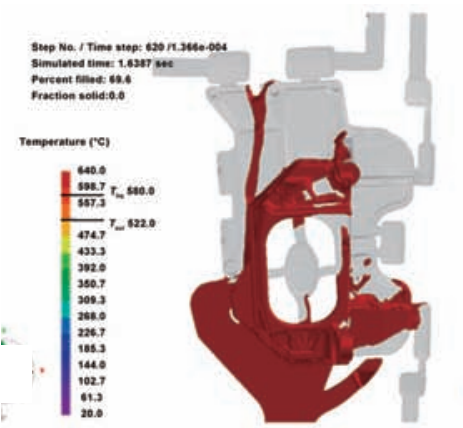

(a1)

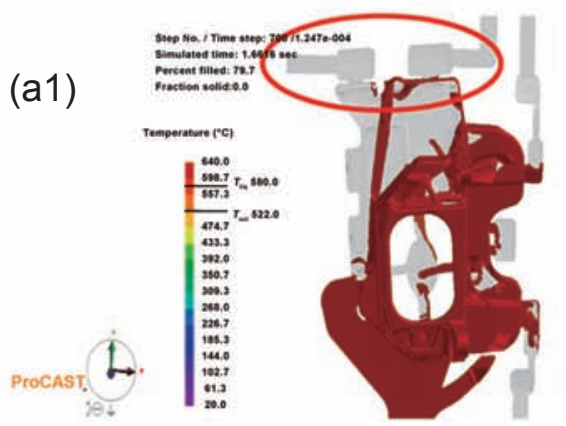

(a2)
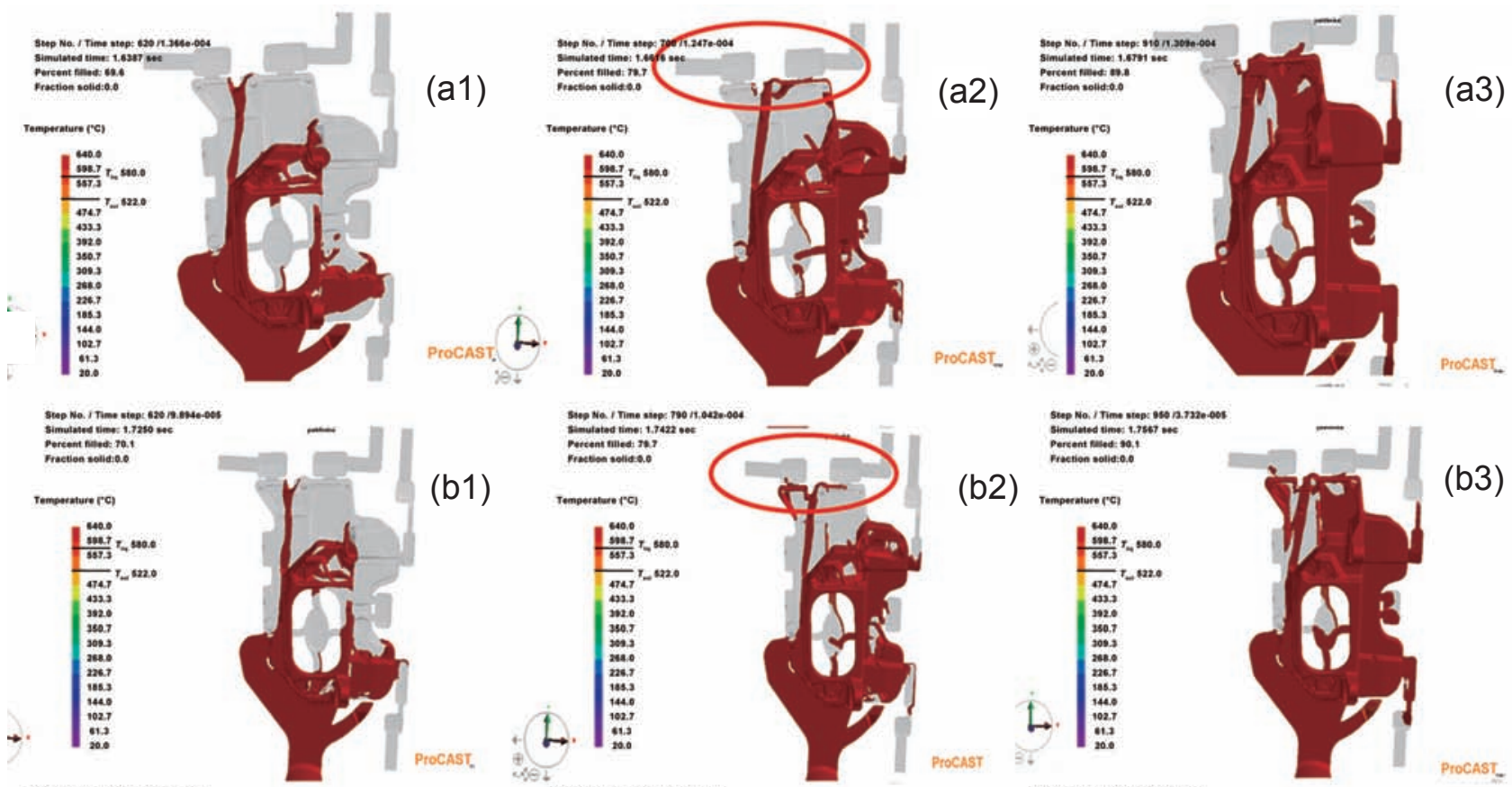

(b1)
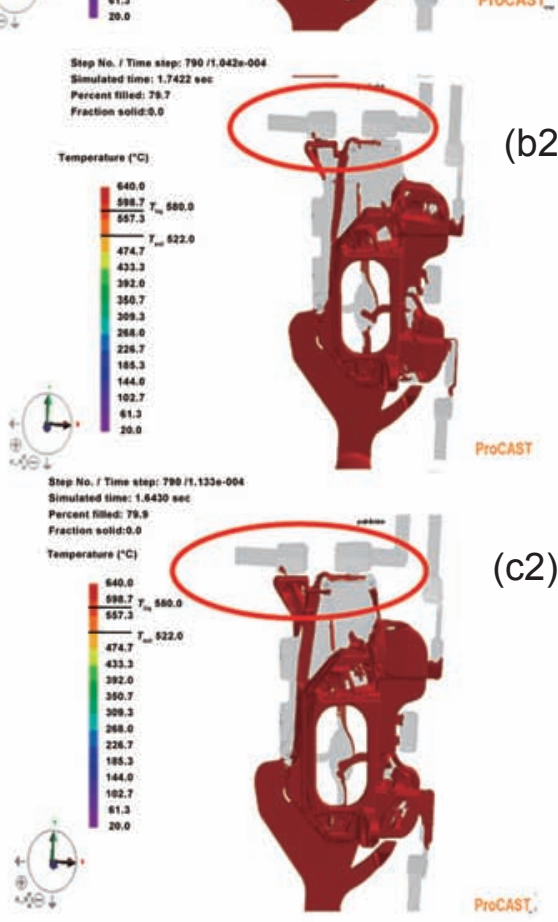

(b2)
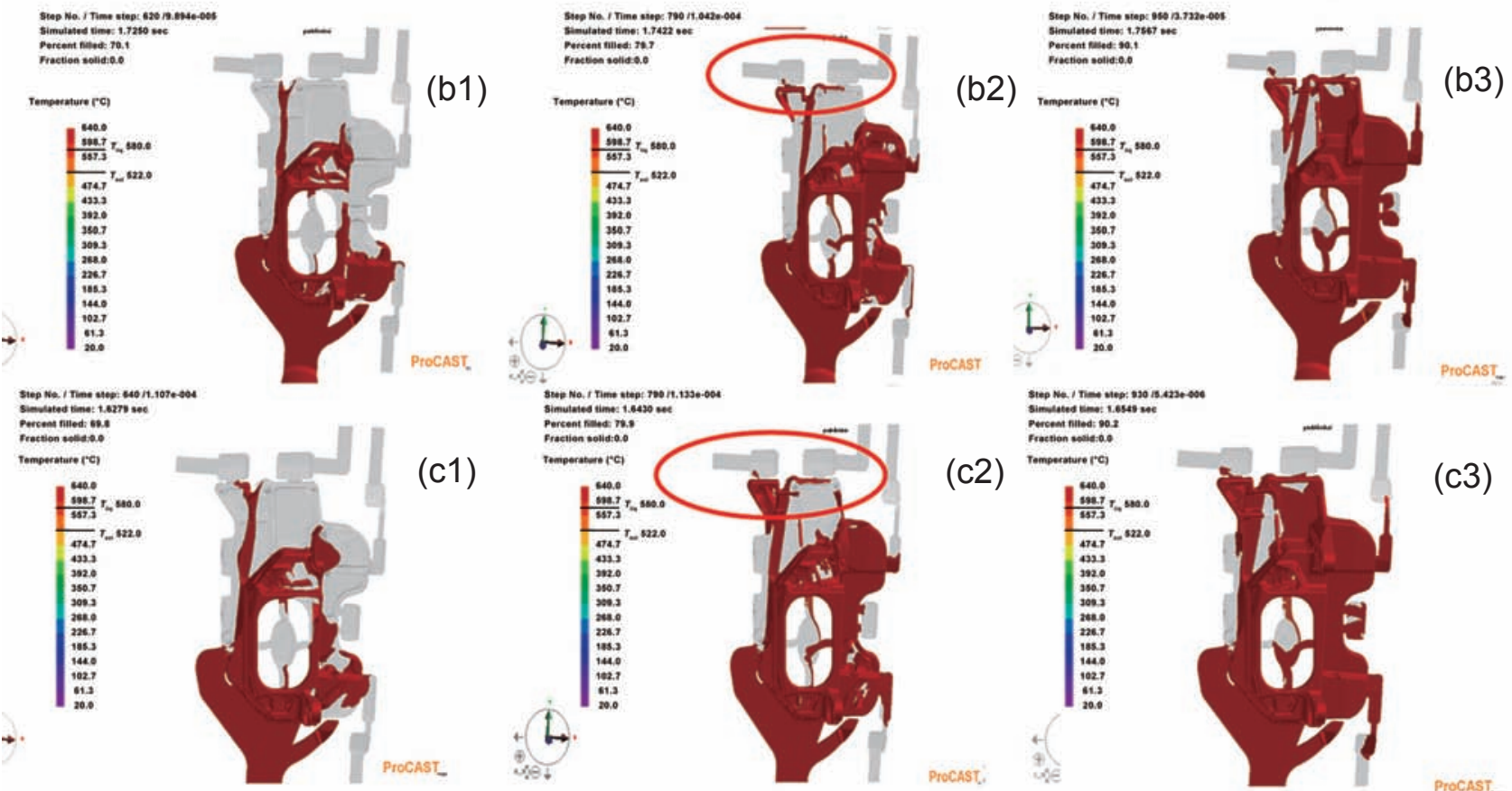

Fig. 7: Filling diagram for different high-pressure velocities: (a1) $2 \mathrm{~m} \cdot \mathrm{s}^{-1}, 70 \%$ filling; (a2) $2 \mathrm{~m} \cdot \mathrm{s}^{-1}, 80 \%$ filling; (a3) 2 $\mathrm{m} \cdot \mathrm{s}^{-1}, 90 \%$ filling; (b1) $2.5 \mathrm{~m} \cdot \mathrm{s}^{-1}, 70 \%$ filling; (b2) $2.5 \mathrm{~m} \cdot \mathrm{s}^{-1}, 80 \%$ filling; (b3) $2.5 \mathrm{~m} \cdot \mathrm{s}^{-1}, 90 \%$ filling; (c1) $3 \mathrm{~m} \cdot \mathrm{s}^{-1}$, $70 \%$ filling; (c2) $3 \mathrm{~m} \cdot \mathrm{s}^{-1}, 80 \%$ filling; (c3) $3 \mathrm{~m} \cdot \mathrm{s}^{-1}, 90 \%$ filling 


\subsection{Experiment verification}

The data obtained from the above simulations were verified by experiment on an YZM-800T die casting machine. The results of

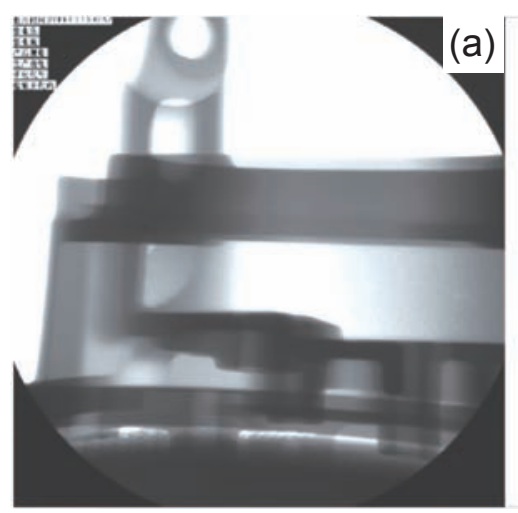

Fig. 8: Side view (a) and front view

\section{Conclusions}

(1) The gating system and the overflow system were designed by analyzing the casting structure, combining with the size of wall thickness. The gating system consists of three runners and one branch. The overflow system contains five overflow slots. Besides, an overflow tank was added at the top of the casting to enhance the gas circulation.

(2) The die casting parameters were simulated and the simulation results show that not only low injection temperature but also lowpressure velocity can lead to a mass of pre-crystallization in the injection chamber. Exorbitant low-pressure velocity can lead to air entrapment. High- and low- velocity switching position should ensure that the liquid metal does not cause an air entrapment in the runner. Exorbitant high-pressure velocity can block the exhaust holes in the final filling position untimely.

(3) According to the simulation results, the optimum die casting parameters are as follows: the injection temperature of $650{ }^{\circ} \mathrm{C}$, low-pressure velocity of $0.2 \mathrm{~m} \cdot \mathrm{s}^{-1}$, high- and low- speed switching position of $320 \mathrm{~mm}$ and high-pressure velocity of $2 \mathrm{~m} \cdot \mathrm{s}^{-1}$.

(4) The optimum die casting parameters, the gating system and the overflow system were verified by experiment. No macro defects were found in the X-ray flaw detection.

\section{References}

[1] Paliani P. Thermoelastic Deformation of Cold Chamber Die Casting Machine Shot Sleeves [MS Thesis]. US: Ohio State University, 1993.

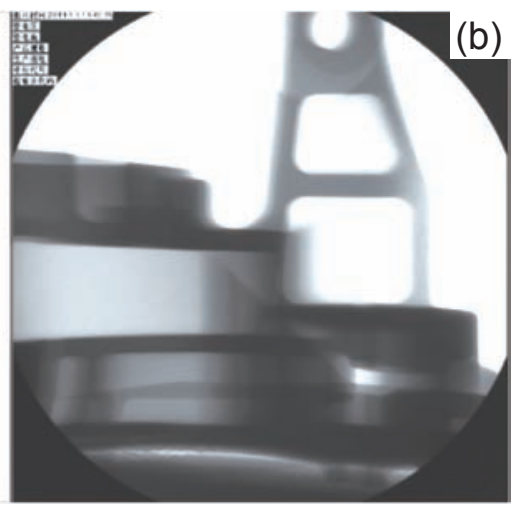

X-ray inspection of the castings are shown in Fig. 8. No shrinkage was found in the aluminum alloy shell. The simulation results can be applied to actual production.

(b) of X-ray detection of casting
[2] El-Mahallawy A N , Taha M A, Pokora E, et al. On the influence of process variables on the thermal conditions and properties of high pressure die-cast magnesium alloys. Journal of Materials Processing Technology, 1997, 73(1): 125-138.

[3] Pitsaris C, Abbott T, Davies C, et al. Influence of Process Parameters on the Microstructure and Mechanical Properties of Magnesium Die Castings. In: Magnesium: Proceedings Applications of the 6th International Conference Magnesium Alloys and Their Applications, 2005.

[4] Syrcos G P. Die casting process optimization using Taguchi methods. Journal of Materials Processing Technology, 2003, 135(1): 68-74.

[5] Kwon H J, Kwon H K. Computer aided engineering (CAE) simulation for the design optimization of gate system on high pressure die casting (HPDC) process. Robotics and ComputerIntegrated Manufacturing, 2018, 55: 147-153.

[6] Kwon H K, Seo K K. Simulation Study on HPDC Process for Automobile Part with Aluminum Alloy. Materials Science Forum, 2013, 761: 4.

[7] Duan H Z, Shen J N, Li Y P. Comparative Analysis of HPDC Process of an Auto Part with ProCAST and FLOW-3D. Applied Mechanics and Materials, 2012, 184-185: 90-94.

[8] Rai J K, Lajimi A M, Xirouchakis P. An intelligent system for predicting HPDC process variables in interactive environment. Journal of Materials Processing Technology, 2008, 203(1-3): 72-79.

[9] Kwon H J, Kwon H K. Computer aided engineering (CAE) simulation for the design optimization of gate system on high pressure die casting (HPDC) process. Robotics and ComputerIntegrated Manufacturing, 2019, 55: 147-153. 